\title{
The Risk and Reward Management in Innovation Portfolios: A Markovian Approach
}

\author{
Sergio J. Chión ${ }^{1}$ and Vincent Charles ${ }^{1, *}$ \\ ${ }^{1}$ CENTRUM Católica Graduate Business School (CCGBS), Lima, Peru \\ Pontificia Universidad Católica del Perú (PUCP), Lima, Peru \\ E-mail: <sjchion@pucp.edu.pe,vcharles@pucp.pe>
}

\begin{abstract}
Today, innovation is perceived as a source of competitive advantage for firms, playing a vital role in both the survival and growth of firms. A general look at the existing literature on innovation points toward a lack of studies that explore the risk and reward topic in the conformation of innovation portfolios in a firm. Hence, the main purpose of the present paper is to analyse the relationship between investment in innovation and the gain of the process and how this relationship is affected by the type of industry in which the firm operates and by the intervention of the authorities (legal protection of innovation). Among others, results indicate that, contrary to what could be expected, firms would tend to invest in disruptive innovation projects in hard innovative industries, wherein the potential, disruptive innovation is much harder to generate given the natural protection against potential competition that characterizes these industries. On the other hand, investment in disruptive innovation in soft innovative industries would require a framework of legal protection in accordance with the level of natural innovativeness of the industry. In terms of practical implications, the management of the legal protection would be socially desirable for achieving a balanced innovation development framework in the economy, as well as for resource allocations in disruptive innovation in industries where, although it is easier to be successful, its usufruct is difficult.
\end{abstract}

Keywords: disruptive innovation, innovation, Markov, management

Received: March 22, 2018; accepted: July 31, 2018; available online: December 13, 2018

DOI: 10.17535 /crorr.2018.0013

\section{Introduction}

Adopted as a response to the continuous changes that the business environment is experiencing, innovation has become one of the main priorities of most companies. Drucker [9] argued that in "a period of rapid change the best - perhaps the only - way a business can hope to prosper, if not survive, is to innovate. This is the only way to convert change into opportunities. This,

\footnotetext{
* Corresponding author.

http://www.hdoi.hr/crorr-journal
}

(02018 Croatian Operational Research Society 
however, requires that innovation itself be organized as a systematic activity". In other words, developing innovation improves the ability of companies to deal with the dramatic changes experienced in the competitive environment [19]. As such, in the field of strategic management, innovation is perceived as a source of competitive advantage for a firm, playing an important role in the survival and growth of firms. But while research has been devoted to analyzing the firm-level strategies employed for sustaining existing competitive advantage, little effort has been placed on understanding how certain firms build competitive advantage in regimes of rapid change [26].

In time, innovation has been defined in many ways, at different levels of analysis (i.e., individuals, organizations, countries). For example, Kimberly [16] distinguished between adoption and diffusion of innovations and Van de Ven and Rogers [28] differentiated between innovation and innovativeness. Innovation refers to the adoption (initiation, development, and implementation) of a new idea or behavior - be it a system, policy, program, device, process, product, or service - by an organization [7]; it can, hence, concern all parts of an organization and its operation. In a more recent study, Baregheh, Rowley, and Sambrook [4] defined innovation as "the multistage process whereby organizations transform ideas into new/improved products/services or processes, in order to advance, compete, and differentiate themselves successfully in their marketplace" (p. 1334). What is to be noted is that embedded in the multiple definitions that exist is the idea that innovation - characterized by an emphasis on change and newness - can be managed.

Research on innovation has generally focused on the nature or degree of innovation and the type of innovation, respectively [5]. On the one hand, the nature or degree of innovation concerns the degree of novelty of an innovation. In this regard, innovation has been generally defined on a dichotomous scale: incremental versus radical innovation [1], continuous versus discontinuous technological changes [24], incremental versus breakthrough innovations [27], conservative versus radical innovations - or competence-destroying or competence-enhancing [2], and sustaining versus disruptive innovations [6]. In this context, a radical innovation assumes a fundamental change, such as a new product or service, whereas an incremental innovation refers to an improvement brought to an existent product or service. This dichotomy was further elegantly elaborated upon by Day [8], who differentiated between the existence of "small projects" and "big projects":

... small projects, which I call "little $i$ " innovations, are necessary for continuous improvement, but they don't give companies a competitive edge or contribute much to the profitability. It's the risky "Big I" projects -new to the company or new to the world- that generate the profits needed to close the gap between revenue forecasts and growth goals. (According to one study, only $14 \%$ of new product launches were substantial innovations, but they accounted for $61 \%$ of all profit from innovations among the companies examined.)

On the other hand, the type of innovation concerns the outcome of the innovation process. Abernathy and Utterback [3], for example, differentiated between product or process innovation, while Francis and Bessant [11] proposed four types of innovation: position, product, process, and paradigm innovation. In a more recent study, Oke, Burke, and Myers [23] advanced three types of innovation: product, service, and process. Product innovation refers to new 
product offerings or improvements in existing products; service innovation encompasses the new developments in the activities that are performed to deliver the core product; and process innovation refers to creating or improving the methods of production, service, or administrative operations (also see [14]).

The existing literature further defines the existence of both red and blue oceans [15]. In brief, the idea behind the red ocean strategy is that the company competes in an existing and well-established marketplace, and exploits the existing demand, while a company employing the blue ocean strategy captures new demand and creates an uncontested market space. The authors proposed that instead of focusing on benchmarking current competitors and defeating them, firms should aim for value innovation by redefining their offerings to provide unique attributes and experiences to a set of unserved customers.

A great number of research studies have been dedicated to studying the factors that influence innovative performance [13]. Many researchers argued that organizational size facilitates innovation [10, 17]. Nord and Tucker [22], for example, advanced that large organizations have more complex and diverse facilities (financial resources, marketing skills, research capabilities, product development experience, among others) to develop a higher number of innovations.

More resources can also help organizations to cope better with the consequences of failed innovations that they may experience. Teece, Pisano, and Shuen [26] emphasized the need to combine different resources, thus giving birth to the dynamic capabilities' approach, which broadly defined, characterizes the ability to achieve new forms of competitive advantage.

Other researchers, however, argued that organizational size does not necessarily translate into higher innovativeness [12], and that small organizations may actually be more innovative because they count with greater flexibility and a higher ability to accept and implement change. Nevertheless, as Damanpour [7] observed, the main reason for finding a negative association between organizational size and innovation could be more methodological than theoretical.

It is also generally believed that $R \& D$ expenditure represents a measure of the capacity of a firm to innovate [21]. Nevertheless, not all firms are or can be R\&D intensive, but this does not stop them from being innovative based on marketing innovation strategies that focus on competitiveness, marketing, or distribution channels [13]. It is well known that following a resource-based strategy is not enough to support sustainable innovation - firms have to be able to also demonstrate timely responsiveness and rapid and flexible product and service innovation, among others.

An interesting result was obtained by Schmidt and Rammer [25] who showed that the combination of technological and non-technological innovation has a positive impact on a firm's return on sales. Lokshin, van Gils, and Bauer [20] analyzed the impact of organizational skills and showed that innovation might be triggered on a higher scale by the combination of customer, technological, and organizational skills.

The above discussion is not and does not aim to be exhaustive, but it can help to pinpoint that several areas of research have been developed in time to understand the complexity posed by the innovation phenomenon. What appears to be generally lacking from the 
Sergio J. Chión and Vincent Charles

innovation literature, however, are studies that explore the risk and reward topic in the conformation of innovation portfolios in a firm. For scholars, the study can be of help in developing a better understanding of the role played by innovation in creating a competitive advantage, while for managers and practitioners, the study can be of help by means of providing insightful thoughts into how innovation could be managed in an increasingly dynamic competitive landscape, wherein multiple angles and facets of both the innovation process and the business environment must be considered. Hence, the objective of this theoretically-oriented paper is to analyze the risk and reward topic in the conformation of innovation portfolios of the firm, taking into account the type of industry and the legal protection of innovation.

The remainder of the paper is organized as follows: the next section describes the setting underpinning the existence of an innovation portfolio in a firm, along with the associated assumptions. Next, the Markovian process and the Markovian model are introduced. Subsequently, the analysis section explores the relationship between investment in innovation and the gain of the process and how this relationship is affected by the type of industry and by the intervention of the authorities. The analysis is further enhanced with a discussion of results and relevant comparisons. The last section concludes the paper.

\section{The Markovian process and modelling}

\subsection{The setting}

We will consider the definition of an innovation portfolio in a firm. The portfolio is defined by the share of the budget for innovation investment between small projects (SPs) and a big project (BP). The SPs are small variations of products, processes, methods, markets, etc. The BP is a disruptive innovation à la Christensen [6] and it represents a major departure from traditional products, markets, technology, and so on. The investment in SPs is secure and their rewards occur in the same period when the investment takes place. The investment in a BP is risky and its reward occurs in future periods. The net reward of the SPs is relatively small with respect to the BP and will not be considered. The BP generates investment in its incubation period, and if successful, it will generate important rewards in the following periods.

It is assumed that innovation depends on the industry to which the firm belongs [18]. Thus, the probability $\beta$ of having a successful BP depends on the industry to which the firm belongs; $\beta$ characterizes the industry and it represents an intrinsic index for the industries, reflecting the natural potentiality to generate disruptive innovation. It is positive and lower than 1. A high $\beta$ corresponds to an industry where innovation is relatively simple to generate, i.e., a Soft-Innovative industry (SI), and a low $\beta$ corresponds to an industry where disruptive innovation is rare and difficult to generate, i.e., a Hard-Innovative industry (HI). In the SI, the potential generation of a successful BP is highly likely, and if generated, it is easy to imitate; therefore, in this type of industries, the BP rewards are smaller and not easy to maintain. On the contrary, in the HI, the potential generation of a successful BP is not very likely and difficult to imitate, the rewards are much bigger and easier to maintain. Disruptive Innovation is socially important, regardless of the type of industry to which it belongs. The type of industry is 
assumed to be defined by this probability $\beta$; thus, it is a continuum characterization of industries in accordance to innovativeness. The probability $\beta$ measures the level of potential natural innovativeness of the industry. It is assumed that the probability of a successful BP, in a given period, depends only on the industry the firm belongs to, in particular, it does not depend on the amount invested in the project.

Whenever the firm enjoys a successful project, it just exploits that project and does not invest in innovation. How long the firm enjoys a successful project will also depend on the industry to which it belongs. The SI industries, characterized by a high $\beta$, have a high probability of both generating and losing the innovation edge by the firm; inversely, the HI industries, characterized by a low $\beta$, have a low probability of both generating and losing the innovation edge by the firm. The probability of losing the innovative edge will also depend on the legal protection of innovation - the higher the protection, the longer the firm will enjoy the success of its BP.

\subsection{Modelling}

Time is defined by discrete periods. In each period, the firm could be in one of two possible states, namely $S_{1}$ and $S_{2}$, see Figure 1. In state $S_{1}$, the firm defines its innovation portfolio, deciding the share $\alpha$ to be invested in the BP, and $(1-\alpha)$ to be invested in the SPs, with $0 \leq$ $\alpha \leq 1$.

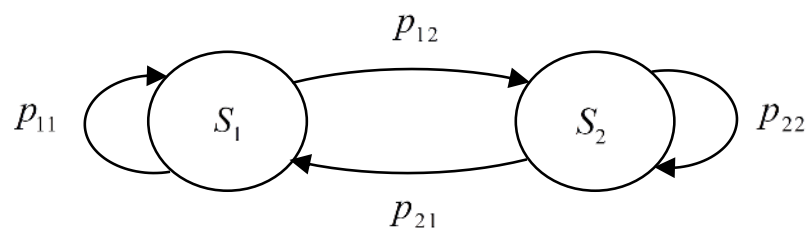

Figure 1: The Markovian process.

In state $S_{1}$, the firm will exploit the net reward of its investment in the SPs in that period, which is considered nil. If the BP is unsuccessful, the firm remains in $S_{1}$ in the following period, with a net reward of $-\alpha$ in the current period, thus $r_{11}=-\alpha$, where $r_{i j}$ denotes the reward for the firm if it makes a transition from $S_{i}$ to $S_{j}$.

If the BP is successful, the firm makes a transition to $S_{2}$ in the following period. In $S_{2}$, the firm exploits the rewards of a successful BP, without making any innovation investment, and $r_{22}=A(1-\beta) \ln (1+\alpha)$, where $A>0$ is a scale coefficient.

Note that, $\partial r_{22} / \partial \beta=-A \ln (1+\alpha)<0$. The BP reward is decreasing with $\beta$. The higher the level of innovativeness, the smaller the rewards for the successful BP. The achievement of a successful project generates a relatively small reward in a SI and a high reward in the case of a HI. 
On the other hand, $\partial r_{22} / \partial \alpha=A(1-\beta)(1 /(1+\alpha)) \geq 0$ and $\partial^{2} r_{22} / \partial \alpha^{2}=-A(1-$ $\beta)\left(1 /(1+\alpha)^{2}\right) \leq 0$. The BP reward is increasing with investment at a decreasing rate. Also, $r_{22}=$ 0 for $\alpha=0$, no investment means no reward.

Let $R$ be the reward matrix, thus:

$$
R=\left[\begin{array}{ll}
r_{11} & r_{12} \\
r_{21} & r_{22}
\end{array}\right]=\left[\begin{array}{cc}
-\alpha & 0 \\
0 & A(1-\beta) \ln (1+\alpha)
\end{array}\right] .
$$

The transition probabilities are defined as follows:

- The transition from $S_{1}$ to $S_{2}$ occurs when the BP is a success; it is assumed that this probability only depends on the type of industry: $p_{12}=\beta$.

- The transition from $S_{1}$ to $S_{1}$ is equivalent of an unsuccessful BP: $p_{11}=1-\beta$.

- The transition from $S_{2}$ to $S_{1}$ is equivalent to losing the innovative edge due to displacement by another innovation in the industry, or imitation: $p_{21}=\beta(1-\delta)$, with $0 \leq \delta \leq$ 1 , where $\delta$ represents the level of legal protection given to a successful BP. The maximum is given by $\delta=1$ and no protection is given by $\delta=0$. Thus, for $\delta=0, p_{21}=\beta$ is symmetrical to $p_{12}$ and represents a natural probability of transition for that industry. For $\delta=1$, representing total protection, the firm will remain in $S_{2}$ forever.

Clearly, $\partial p_{21} / \partial \delta=-\beta \leq 0 ; p_{21}$ is decreasing with the level of protection at a constant rate. Also, $\partial p_{21} / \partial \beta=1-\delta \geq 0$; the transition probability increases with the level of innovativeness in the industry.

- The transition from $S_{2}$ to itself is equivalent to maintaining the innovative edge: $p_{22}=1$ $-\beta(1-\delta)$.

Thus, the transition probability matrix is:

$$
T=\left[\begin{array}{ll}
p_{11} & p_{12} \\
p_{21} & p_{22}
\end{array}\right]=\left[\begin{array}{cc}
1-\beta & \beta \\
\beta(1-\delta) & 1-\beta(1-\delta)
\end{array}\right] .
$$

Note that assumptions are such that the transition probabilities do not depend neither on the levels of investment nor on the parameter of scale $A$; they only depend on the type of industry and on the legal protection.

Thus, the Markovian model is defined by Figure 1 and by the Reward (1) and Transition (2) matrices $R$ and $T$, respectively with $0 \leq \alpha \leq 1,0<\beta<1,0 \leq \delta<1, A \geq 0$.

Note that $\beta$ excludes the extreme values of 0 and 1 , also $\delta$ excludes the value of 1 . These extreme values correspond to degenerative cases. The value of $\beta=0$ corresponds to a system that will remain forever in its starting state, either $S_{1}$ or $S_{2}$. The joint values of $\beta=1$ and $\delta=0$ correspond to an oscillating process alternating continuously between $S_{1}$ and $S_{2}$. The value of $\delta=1$ corresponds to a system that eventually will always remain in $S_{2}$.

The asymptotical behavior of this Markovian model is defined by the components of the left unitary eigenvector of $\mathrm{T}$ associated to the largest eigenvalue. Thus,

$$
\begin{gathered}
\Pi_{1}=\left(1-p_{22}\right) /\left(1-p_{22}+p_{12}\right), \\
\Pi_{2}=p_{12} /\left(1-p_{22}+p_{12}\right),
\end{gathered}
$$


where $\Pi_{1}$ and $\Pi_{2}$ are the limiting state probabilities for states $S_{1}$ and $S_{2}$, respectively. Given that the process is completely ergodic, after a great number of transitions, the system will be in $S_{1}$ with probability $\Pi_{1}$ and in $S_{2}$ with probability $\Pi_{2}$, regardless of the starting state. Replacing the respective probabilities, we obtain $\Pi_{1}=(1-\delta) /(2-\delta)$ and $\Pi_{2}=1 /(2-\delta)$.

Thus, $\Pi_{1}$ and $\Pi_{2}$ do not depend on $\beta$, they only depend on $\delta$, the legal protection; this is a consequence of the fact that transition probabilities between both states, $p_{12}$ and $p_{21}$, only differ in the factor $(1-\delta)$ and in the symmetry of these transition probabilities in $\beta$.

For $\delta=0, \Pi_{1}=\Pi_{2}=0.5$, which is explained for the symmetry in the probability assignments between $S_{1}$ and $S_{2}: p_{12}=p_{21}=\beta$ and $p_{11}=p_{22}=1-\beta$.

In addition:

- $\quad d_{\Pi_{1}} / d \delta=-1 /(2-\delta)^{2}<0$ and $d^{2} \Pi_{1} / d \delta^{2}=-2 /(2-\delta)^{3}<0$.

$\Pi_{1}$ decreases with $\delta$ at a decreasing rate (in sign, not in magnitude).

- $\quad d_{\Pi_{2}} / d \delta=1 /(2-\delta)^{2}>0$ and $d^{2} \Pi_{2} / d \delta^{2}=2 /(2-\delta)^{3}>0$.

$\Pi_{2}$ increases with $\delta$ at an increasing rate.

Figure 2 depicts the behavior of the limiting state probability. Without legal protection, the limiting state probability of 0.5 indicates that, after long enough transitions, the system will be in $S_{1}$ or $S_{2}$ with equal probabilities. Another interpretation is that, for $\delta=0$, in the long run, the system will be either in $S_{1}$ or $S_{2}$, with equal chances. Observe that these probabilities do not depend on the level of investment $\alpha$ in BP, even if $\alpha=0$, in the long run, the number of periods the system will be in $S_{1}$ is equal to the number of periods it will remain in $S_{2}$; though in this last state the reward of having a successful $\mathrm{BP}$ will be null, for $r_{22}=0$, i.e., no investment was made.

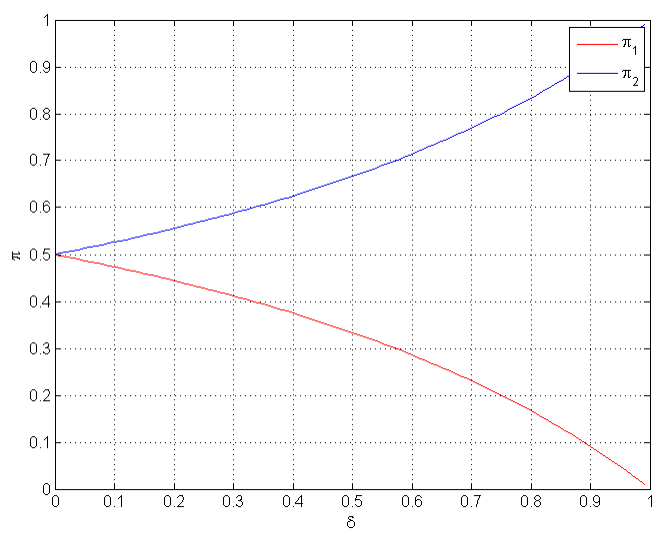

As the legal protection increases, Figure 2 shows that the limiting state probability of being in $S_{1}$ decreases and, correspondingly, the limiting state probability of $S_{2}$ increases; this behavior is explained by the higher protection of a successful BP. At the extreme of total protection, firms would eventually be in $S_{2,}$ enjoying the rewards of a successful BP - there would be no new investment and no innovation; hence, this case will not be considered.

Figure 2: Asymptotic behavior (limiting state probabilities).

On the other hand, the expected transition reward is given by $q^{T}=\left[q_{1}, q_{2}\right]$, with:

$$
\begin{aligned}
& q_{1}=p_{11} r_{11}+p_{12} r_{12}=-(1-\beta) \alpha, \\
& q_{2}=p_{21} r_{21}+p_{22} r_{22}=(1-\beta(1-\delta)) A(1-\beta) \ln (1+\alpha),
\end{aligned}
$$


where $q_{1}$ represents the expected reward of the next transition, if the firm is currently in $S_{1}$, similar for $q_{2}$.

We are interested in the gain of the system $g=\Pi^{T} q=\Pi_{1} q_{1}+\Pi_{2} q_{2}$, where $\Pi^{T}=\left[\Pi_{1}, \Pi_{2}\right]$; hence,

$$
g=[(1-\delta) /(2-\delta)][-(1-\beta) \alpha]+[1 /(2-\delta)][1-\beta(1-\delta)][A(1-\beta) \ln (1+\alpha)]
$$

which is the expected reward per transition for the firm under asymptotic behavior.

\section{Scenario-based analytics}

Our main interest is in analyzing the relationship between investment in innovation, represented by the share $\alpha$ of resources allocated to the BP, and the gain $g$ of the process; and how this relationship is affected by the industry in which the firm operates, represented by $\beta$, and by the intervention of the authorities, represented by $\delta$.

The situation can be seen as firms trying to maximize the gain $g$ by manipulating the innovation portfolio structure $\alpha$; and authorities trying to influence that decision by manipulating $\delta$ to maximize the innovation investment $\alpha$, in accordance with the industry $\beta$.

The analysis of the Markovian process will be made first for the case of no protection $(\delta$ $=0)$ and thereafter protection will be considered $(0<\delta<1)$. Then, both sets of results will be compared. Finally, the results and related comparisons will be shown for different values of $A$.

Though the case of no protection can be treated analytically $(\delta=0)$, the general case of free $\delta$ becomes analytically too cumbersome; therefore, we will handle both cases and its comparison through numerical simulation. For this purpose, we will consider:

- $\quad$ Scale factor $A$ : Positive values, $A>0$. Specifically, 1, 2, 3, and 5;

- Industry type $\beta$ : Values from 0.1 to 0.9 , with increments of 0.1 ;

- Investment in BP $\alpha$ : Values from 0.0 to 1.0, with increments of 0.1;

- Levels of incentives $\delta$ : Values from 0.0 to 0.9 , with increments of 0.1 .

\subsection{Case of no protection: $\delta=0$}

For $A=2$ and $\delta=0$, and different combinations of $\beta$ and $\alpha$, numerical calculations for gain $g$ $=g(A=2, \delta=0, \beta, \alpha)$ were found ${ }^{1}$. For each value of $\beta$, the $\alpha^{+}=\alpha^{+}(\beta)$ that maximizes the gain was selected: $\alpha^{+}(\beta)$ is such that $g^{+}=g^{+}\left(\beta, \alpha^{+}(\beta)\right) \geq g(\beta, \alpha)$ for a given $\beta$ and any $\alpha$.

Specifically, for each $\beta$ from 0.1 to $0.9^{2}$, with increments of 0.1 , and values of $\alpha$ ranging from 0 to 1 with increments of 0.1 , the gain $g=g(\beta, \alpha)$ was calculated. For each $\beta$, the $\alpha$ that maximizes $g(\beta, \alpha)$ was selected:

\footnotetext{
${ }^{1}$ For simplicity, given that $A$ and $\delta$ will remain fixed in this section, we represent $g$ as depending only on $\beta$ and $\alpha$.
} 


$$
(\beta, \alpha) \rightarrow g(\beta, \alpha) \rightarrow \alpha^{+}(\beta) / g^{+}\left(\beta, \alpha^{+}(\beta)\right) \geq g(\beta, \alpha) .
$$

For each $\beta, \alpha^{+}=\alpha^{+}(\beta), g^{+}=g^{+}\left(\beta, \alpha^{+}(\beta)\right), \Pi_{1}{ }^{+}=\Pi_{1}{ }^{+}\left(\beta, \alpha^{+}(\beta)\right)$, and $\Pi_{2}{ }^{+}=\Pi_{2}{ }^{+}\left(\beta, \alpha^{+}(\beta)\right)^{3}$ were found. Table 1 and Figure 3, as an example, show the results for the specific case of $A=2$, $\delta=0$ and $\beta=0.4$, for $\alpha=0.0,0.1,0.2, \ldots, 0.9,1.0$.

\begin{tabular}{|l|r|r|r|r|r|r|r|r|r|r|r|}
\hline $\boldsymbol{\alpha}$ & 0 & 0.1 & $\alpha^{+}=0.2$ & 0.3 & 0.4 & 0.5 & 0.6 & 0.7 & 0.8 & 0.9 & 1 \\
\hline $\boldsymbol{g}$ & 0 & 0.004 & $g^{+}=0.006$ & 0.005 & 0.001 & -0.004 & -0.011 & -0.019 & -0.028 & -0.039 & -0.051 \\
\hline $\boldsymbol{\Pi}_{\mathbf{1}}$ & 0.5 & 0.5 & $\Pi_{1}{ }^{+}=0.500$ & 0.5 & 0.5 & 0.5 & 0.5 & 0.5 & 0.5 & 0.5 & 0.5 \\
\hline $\boldsymbol{\Pi}_{2}$ & 0.5 & 0.5 & $\Pi_{2}{ }^{+}=0.5$ & 0.5 & 0.5 & 0.5 & 0.5 & 0.5 & 0.5 & 0.5 & 0.5 \\
\hline
\end{tabular}

Table 1: System behavior $(A=2, \delta=0, B=0.4)$.

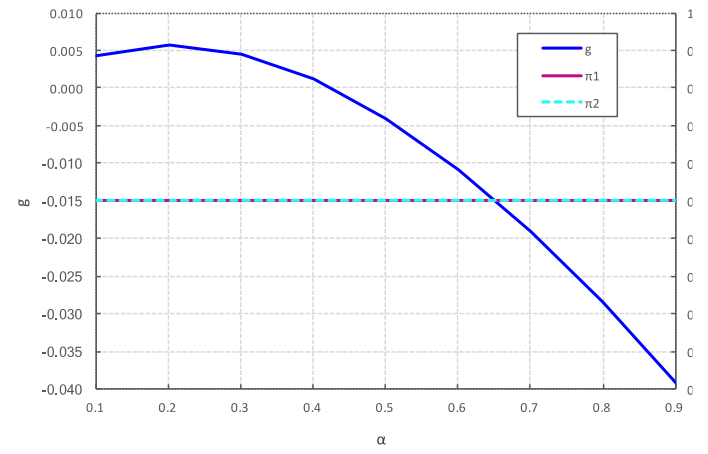

Figure 3: Gain behavior E limiting state probabilities $(A=2, \delta=0, B=0.4)$.

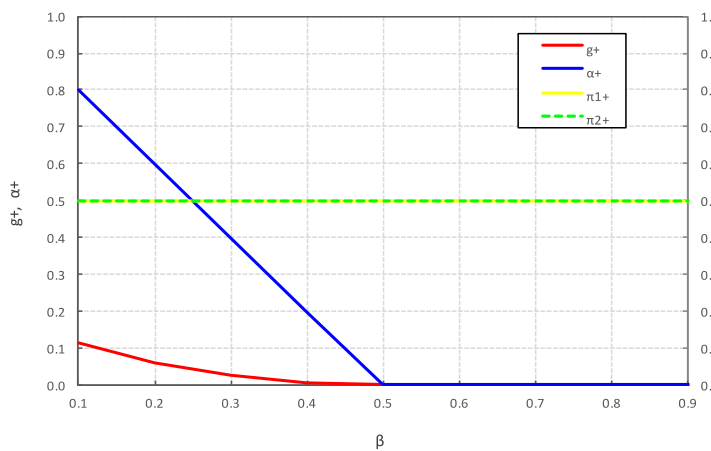

Figure 4: Optimal investment, limiting state probabilities, \& gain $(A=2, \delta=0)$.

From Table 1 and the depiction of gain behavior in Figure 3, it can be seen that the gain increases for low values of the BP investment reach a maximum and thereafter start decreasing. This behavior is generated by two opposing forces, the first one corresponding to an investment cost for the firm of $-\alpha$ per period every time the project is not successful; and the second one corresponding to an increasing reward with the size of the investment $\alpha$, per period, if the project is successful and remains as such. The net balance of these forces generates the behavior shown by the gain behavior in Figure 3, which corresponds to a particular industry represented by $\beta=0.4$. For this industry, the optimal level of innovation investment is achieved

${ }^{2}$ The cases of $\beta=0$ and $\beta=1$ are degenerative cases. For $\beta=0$, we have two disconnected states, $S_{1}$ and $S_{2}$, without interaction between them, thus, the system will remain in the starting state. For $\beta=1$, there is an oscillating system, alternating between $S_{1}$ and $S_{2}$ in every period, but these cases will not be considered. ${ }^{3}$ Actually, as we have seen, $\Pi_{1}{ }^{+}=\Pi_{1}+\left(\beta, \alpha^{+}(\beta)\right)$ and $\Pi_{2}{ }^{+}=\Pi_{2}{ }^{+}\left(\beta, \alpha^{+}(\beta)\right)$ only depend on $\delta$, and in this particular case of $\delta=0$, both are equal to 0.5 . 
at $\alpha=0.2^{4}$. Neither lower nor higher level of investment is convenient for the firm after a long number of transitions.

On the other hand, the limiting state probabilities in Figure 3 show that after long enough number of transitions, the probabilities of being in any one of the states, unsuccessful or successful BP, are equal; this is a consequence of the symmetrical probabilities involved in the state transitions. This behavior does not depend on the level of investment in innovation, only on the level of protection but, given that authorities do not intervene $(\delta=0)$, both probabilities are equal. Thus, even under the policy of no investment, $\alpha=0$, the firm will be in both states with equal probabilities, after long enough transitions. In the case of $\alpha=0$, being in the successful state of $S_{2}$ does not generate a reward for the firm, it trivially avoids the cost of - $\alpha$ of state $S_{1}$, for $\alpha=0$.

The above results correspond to an industry characterized by a type $\beta=0.4$ of innovativeness. Table 2 and Figure 4 show for different types of industries, the optimal levels of innovation investment and its consequences in terms of gain and limiting state probabilities. The results shown depend on the assumption of a scale factor of $A=2$.

\begin{tabular}{|c|r|r|r|r|r|c|c|c|c|}
\hline $\boldsymbol{\beta}$ & 0.1 & 0.2 & 0.3 & 0.4 & 0.5 & 0.6 & 0.7 & 0.8 & 0.9 \\
\hline $\boldsymbol{\alpha}^{+}$ & 0.8 & 0.6 & 0.4 & 0.2 & 0.0 & 0.0 & 0.0 & 0.0 & 0.0 \\
\hline $\boldsymbol{g}^{+}$ & 0.1161 & 0.0608 & 0.0249 & 0.0056 & 0.0 & 0.0 & 0.0 & 0.0 & 0.0 \\
\hline $\boldsymbol{\pi}_{\mathbf{1}}^{+}$ & 0.5 & 0.5 & 0.5 & 0.5 & 0.5 & 0.5 & 0.5 & 0.5 & 0.5 \\
\hline $\boldsymbol{\pi}_{2}{ }^{+}$ & 0.5 & 0.5 & 0.5 & 0.5 & 0.5 & 0.5 & 0.5 & 0.5 & 0.5 \\
\hline
\end{tabular}

Table 2: Optimal system behavior $(A=2, \delta=0)$.

Observe that $\alpha^{+}$is decreasing with $\beta$ : as the industry's level of innovativeness increases, the optimal level of investment in the BP decreases. The reason behind is that for a low level of innovativeness of the industry, HI industries, it pays to allocate a high amount of resources for the BP, as potential rewards compensate the low probability of a successful BP. This compensation is explained by the bigger rewards, $r_{22}$, and the low probability of losing the innovative edge in this type of industry, shown by the transition probability $p_{21}=\beta$ - hence, the firm remains enjoying the rewards of a successful BP for longer periods. The opposite occurs with high levels of $\beta$, in this type of industry, SI industries, though the probability of obtaining a successful BP is higher, the rewards to be obtained do not compensate the investment of $-\alpha$ in state $S_{1}$, due to both the lower reward $r_{22}$ and the high probability of losing the innovative edge. Hence, under a situation of "no authorities" intervention $(\delta=0)$, the investment in innovation will be concentrated in the industry's low level of innovativeness, the HI industries.

On the other hand, as explained before, no matter the type of industry, firms will remain in each state similar number of periods, after a long number of transitions.

Finally, note the decreasing behavior of the gain; the higher the level of innovativeness of the industry, the lower the optimal gain to be obtained by the firm, given that the optimal

\footnotetext{
${ }^{4}$ For the particular values considered in the numerical simulation.
} 
level of investment is also decreasing; all of this is a consequence of the fact that for SI industries, the potential competition becomes higher, with decreasing rewards and an increasing probability of losing the competitive edge. This last increasing probability reduces the period of enjoyment of the rewards of a BP success. This potential competition is due to the easiness of imitating the successful BP, within a system with no protection to innovativeness.

\subsection{The case of protection: $0 \leq \delta<1$}

Let us consider that the authorities are trying to incentivize innovation by fixing $\delta$ in accordance with the industry. For this purpose, consider that the authorities value as a "reward" for the society the equivalent of the firm's investment, $\alpha$, each time the firm gets a successful BP, and makes a transition from $S_{1}$ to $S_{2}$. On the other hand, the authorities consider a loss for the society the null innovation investment that takes place every period the firm remains in $S_{2}$ with a successful BP. But, likewise, authorities only consider the loss in terms of a potentially successful BP that could have been obtained if investment had been made. Thus, each time the firm remains in $S_{2}$, a negative reward of $\alpha \beta$ is considered; $\alpha$ representing the investment not made and $\beta$ representing the probability of a successful BP. Therefore, we have the same Markovian process for the authorities, but with a reward matrix:

$$
V=\left[\begin{array}{ll}
v_{11} & v_{12} \\
v_{21} & v_{22}
\end{array}\right]=\left[\begin{array}{cc}
0 & \alpha \\
0 & -\alpha \beta
\end{array}\right]
$$

The firm has the same reward matrix as before:

$$
R=\left[\begin{array}{ll}
r_{11} & r_{12} \\
r_{21} & r_{22}
\end{array}\right]=\left[\begin{array}{cc}
-\alpha & 0 \\
0 & A(1-\beta) \ln (1+\alpha)
\end{array}\right]
$$

The transition probability matrix is the same, for both the authorities and the firm:

$$
T=\left[\begin{array}{ll}
p_{11} & p_{12} \\
p_{21} & p_{22}
\end{array}\right]=\left[\begin{array}{cc}
1-\beta & \beta \\
\beta(1-\delta) & 1-\beta(1-\delta)
\end{array}\right] .
$$

This transition probability matrix implies the following limiting state probabilities $\Pi_{1}=$ $(1-\delta) /(2-\delta)$ and $\Pi_{2}=1 /(2-\delta)$.

Assuming as before $A=2$, let us consider the situation from the point of view of the authorities, assuming that the firm follows its optimal strategy $\alpha=\alpha^{+}=\alpha^{+}(\delta, \beta)$. The problem of the authorities is to fix $\delta$ to maximize its gain. Let us find the gain for the authorities:

The expected transition reward is given by $h^{T}=\left[h_{1}, h_{2}\right]$, with:

$$
\begin{gathered}
h_{1}(\delta, \beta, \alpha)=p_{11} v_{11}+p_{12} v_{12}=\beta \alpha, \\
h_{2}(\delta, \beta, \alpha)=p_{21} v_{21}+p_{22} v_{22}=[1-\beta(1-\delta)][-\alpha \beta],
\end{gathered}
$$


where $h_{i}$ represents the next expected transition reward for the authorities if the firm was in state $S_{i}$

The gain for the authorities, the asymptotic expected reward per period, becomes:

$$
w(\delta, \beta, \alpha)=\Pi^{T}(\delta) h(\delta, \beta, \alpha)=[\beta \alpha /(2-\delta)][\beta(1-\delta)-\delta] .
$$

A numerical simulation for $A=2$ was performed, for the values specified above, as follows:

- $\quad$ For each $\beta$

$\circ$ For each $\delta$

- For each $\alpha$

- Calculate $g(\delta, \beta, \alpha), w(\delta, \beta, \alpha), \Pi_{1}(\delta), \Pi_{2}(\delta)$

- Select $\alpha=\alpha^{+}(\delta, \beta)$ such that $g\left(\delta, \beta, \alpha^{+}(\delta, \beta)\right) \geq g(\delta, \beta, \alpha)$ for any $\alpha$

- Consider the values of

- $g=g^{+}\left(\delta, \beta, \alpha^{+}(\delta, \beta)\right), w=w^{+}\left(\delta, \beta, \alpha^{+}(\delta, \beta)\right), \Pi_{1}(\delta), \Pi_{2}(\delta)$

- Select $\delta=\delta^{+}(\beta)$ such that:

$w^{+}\left(\delta^{+}(\beta), \beta, \alpha^{+}\left(\delta^{+}(\beta), \beta\right)\right) \geq w^{+}\left(\delta, \beta, \alpha^{+}(\delta, \beta)\right)$ for any $\delta$

$\circ$ Consider the values of

- $\delta^{*}(\beta)=\delta^{+}(\beta)$

- $\alpha^{*}\left(\delta^{*}(\beta), \beta\right)=\alpha^{+}\left(\delta^{*}(\beta), \beta\right)$

- $g^{*}\left(\delta^{*}(\beta), \beta, \alpha^{*}\left(\delta^{*}(\beta), \beta\right)\right)=g^{+}\left(\delta^{*}(\beta), \beta, \alpha^{*}\left(\delta^{*}(\beta), \beta\right)\right)$

- $w^{*}\left(\delta^{*}(\beta), \beta, \alpha^{*}\left(\delta^{*}(\beta), \beta\right)\right)=w^{+}\left(\delta^{*}(\beta), \beta, \alpha^{*}\left(\delta^{*}(\beta), \beta\right)\right)$

- $\Pi_{1}^{*}\left(\delta^{*}(\beta)\right)$ and $\Pi_{2}{ }^{*}\left(\delta^{*}(\beta)\right)$

- In addition, the following ratios were calculated:

- The ratio of authorities and firm gain: $w^{*}\left(\delta^{*}(\beta), \beta, \alpha^{*}\left(\delta^{*}(\beta), \beta\right)\right) / g^{*}\left(\delta^{*}(\beta), \beta, \alpha^{*}\left(\delta^{*}(\beta), \beta\right)\right)$

- The ratio of firm gain with protection and firm gain without protection: $g^{*}\left(\delta^{*}(\beta), \beta, \alpha^{*}\left(\delta^{*}(\beta), \beta\right)\right) / g^{+}\left(\delta=0, \beta, \alpha^{+}(\delta=0, \beta)\right)$

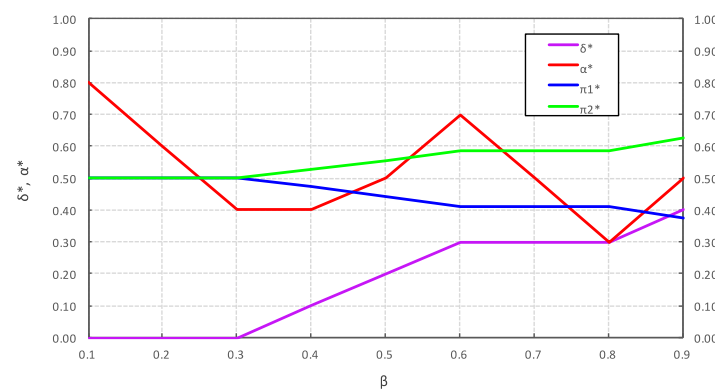

Figure 5: Optimal protection, investment, $\mathcal{E}$ limiting state probabilities $(A=2)$.

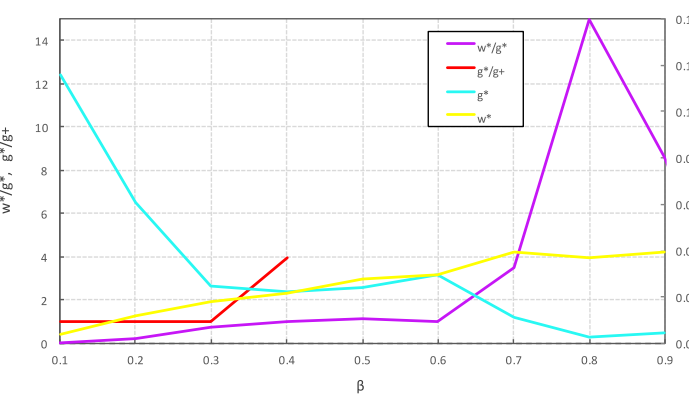

Figure 6: The optimal gains and gains ratio of the firm and the authorities, \&f the optimal protection - no protection gains ratio $(A=2)$. 
Table A1 in the Appendix (see the case of $A=2$ ) and Figures 5 and 6 show the results obtained from the numerical simulations. The following general behavior can be appreciated:

\section{- Hard innovative industries}

Hard Innovative industries, industries with a $\beta$ of up to 0.3 , do not require any protection (Column (2)), the natural protection is enough to foster investment in Disruptive Innovation, generating benefits for both firms and society (Columns (4) and (5)). In these industries, the investment in disruptive innovation is decreasing with the level of innovativeness of the industry, it decreases from 0.8 to 0.4 (Column (3)). Note that the gain is increasing for authorities and decreasing for firms, with the level of innovativeness $\beta$ (Columns (4) and (5)); thus, for these industries, there is no conflict between the interests of the authorities and the firms, though the difference in gains shortens with the level of innovativeness. For all these industries, the authorities' gains are smaller than the firms' gains, though the ratio is increasing (Column (8)) and, obviously, the gains for the firm with and without protection are equal (Column (9)). Given that there is no protection, with $\delta=0$, the symmetry of the transition probability matrix implies an equal limiting state probability of 0.5 (Columns (6) and (7)).

\section{- Intermediate innovative industries}

For these industries, with $\beta$ ranging from 0.4 to 0.6 , the firms' gain without protection has decreased at a level such that protection is needed for investment in disruptive innovation (Column (5)). This protection starts at the low level of 0.1 , but increases up to 0.3 with $\beta$ (Column (2)). The decreasing behavior of investment in BPs reverses its tendency for an increasing behavior (Column (3)); this increasing behavior could be affected by the discretization of the problematic, and it could be stabilized at the level of investment of 0.5. Hence, through protection, the level of investment in innovation is maintained, counteracting the loss of natural attractiveness of the firms in BPs in the case of the reduction of natural protection from imitation, due to the increase in $\beta$. The authorities' gains still show an increasing behavior, but with a tendency to stabilization (Column (4)), and the firms' gains stop decreasing, showing a somewhat stable level (Column (5)) - the gain ratio stabilizes around one, showing similar gains for both parties. The firms' gains with protection experiment a high increase compared to the gains without protection (Column (9)). The limiting state probability decreases for the failure state, stabilizing at 0.41 , while the corresponding probability for the successful state increases, stabilizing at 0.59 .

\section{- Soft innovative industries}

These industries correspond to a $\beta$ ranging from 0.7 to 0.9 , which shows a stabilization of the level of protection between 0.3 and 0.4 (Column (2)) and the investment in disruptive innovation stabilizes between 0.4 and 0.5 (Column (3)). The authorities' gains increase when compared to the Intermediate Industries, but stabilize at a level around 0.4 (Column (4)), while the firms' gains continue to decrease, showing an exhaustion of the capacity of protection to counteract the lack of natural protection in these industries from imitation. This exhaustion is explained by the cost for the authorities that is generated by the firms remaining in the state $S_{2}$, 
which is reflected by the limiting state probabilities (Columns (6) and (7)), wherein $\Pi_{1}$ decreases up to 0.38 and $\Pi_{2}$ increases up to 0.62 . In these industries, the gains for the authorities are much bigger than those for the firms and are also increasing (Column (8)). The relation between the gains for firms with and without protection is undefined, for incommensurability (Column (9)).

\subsection{Scale factor A}

Table A1 in the Appendix and Figures 7, 8, 9, and 10 show the problematic that arises for different scale factors; specifically, for $A=1, A=2$ (already discussed previously), $A=3$, and $A=5$. The scale factor affects the magnitude of the reward for having a successful BP for the firm; the higher the scale factor, the bigger the reward. General conclusions are that with the increment of the scale factor, the number of industries requiring protection reduces, as does the level of protection; the level of investment in disruptive innovation increases; the ratio of optimal gain for the government in relation to the optimal gain for the firm reduces; the same can be observed with regards to the relation between the optimal firm gain with protection and the optimal firm gain with no protection. Furthermore, note that for $A=1$, no protection is required and no investment in disruptive innovation takes place, as a consequence of the low level of reward for having a successful project.

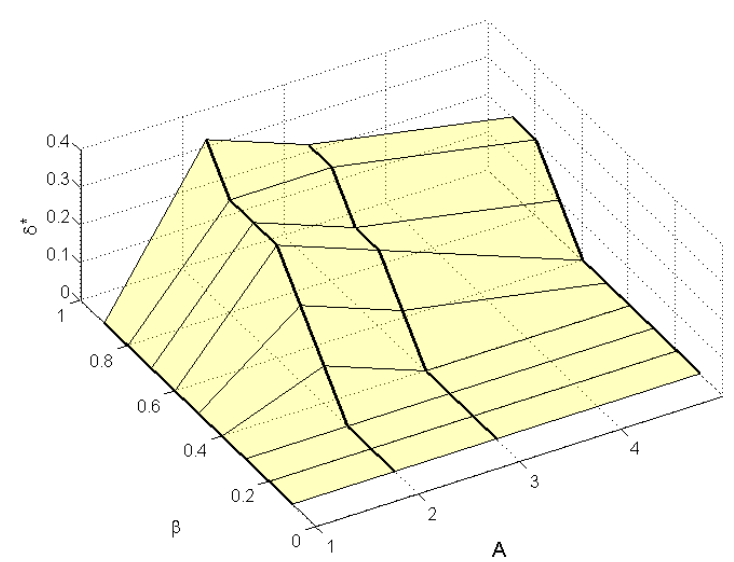

Figure 7: The optimal level of protection for different scale factors.

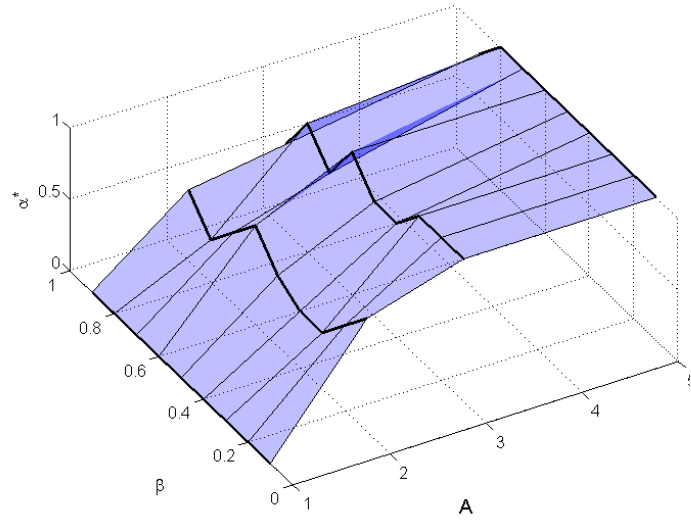

Figure 8: The optimal level of investment for different scale factors. 


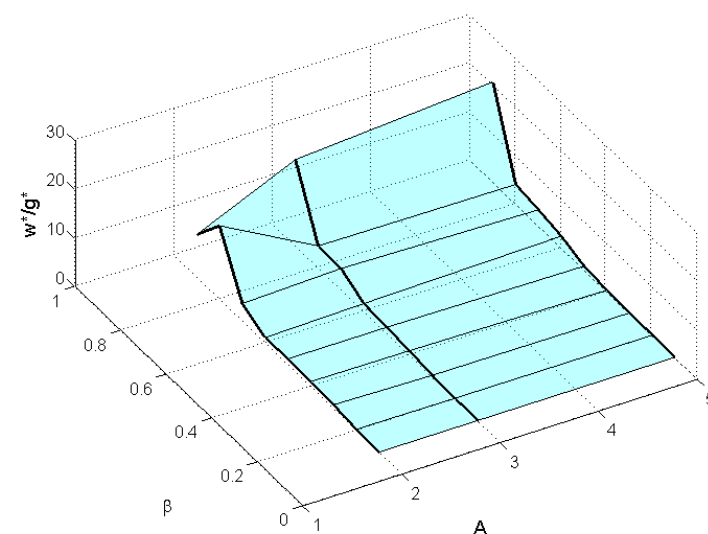

Figure 9: The optimal gains ratio of the firm and the authorities for different scale factors.

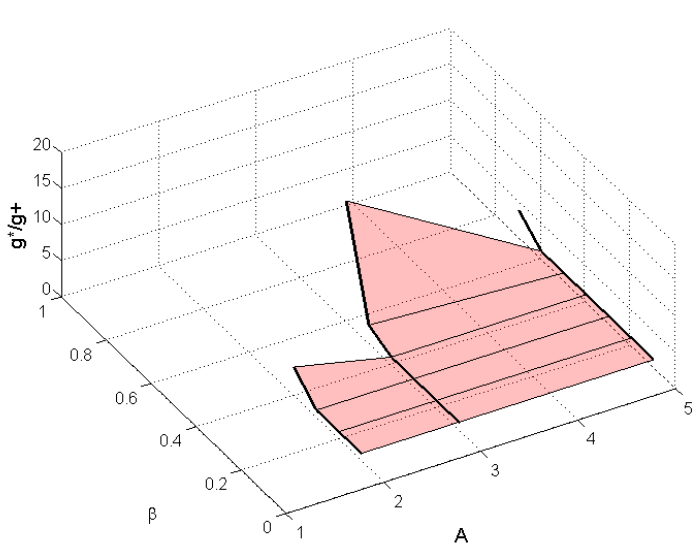

Figure 10: The optimal gains ratio of the firm for the protection and no protection cases, for different scale factors.

\section{Conclusion}

The purpose of the present paper was to analyse the relationship between investment in innovation and the gain of the process and how this relationship is affected by the type of industry in which the firm operates and by the intervention of the authorities (legal protection of innovation).

The results indicate that, somehow contrary to what could be expected, firms would tend to invest in disruptive innovation projects in Hard Innovative industries instead of Soft Innovative industries; in other words, in industries where the potential, disruptive innovation is much harder to generate given the natural protection against potential competition and imitation of successful BPs. The investment in Soft Innovative industries, where the disruptive innovation is potentially easier to achieve, would be somewhat neglected, only SP investments would be taken up in those industries.

Furthermore, investment in disruptive innovation in Soft Innovative industries would require a framework of legal protection in accordance with the level of natural innovativeness of the industry. This protection could be socially desirable for a balanced development of innovation in the economy, as well as for resource allocations in disruptive innovation in industries where it is easier to be successful. A balanced innovation development framework in the economy could also benefit Hard Innovative industries.

The introduction of legal protection to counterbalance the lack of investment in disruptive innovation, due to the short-term life of a successful BP in Hard Innovative industries, would foster this investment up to some limit. This limit, which defines a saturation effect for the protection policy, is generated by the parallel opposing effects of inhibiting investment in innovation by firms that are enjoying a successful BP. Thus, the authorities would have to balance the opposing forces of the incentives to invest in successful BPs and the disincentives for investment while enjoying successful BPs. 
The scale factor affects the magnitude of the reward for having a successful BP for the firm; the higher the scale factor, the bigger the reward. General conclusions are that with the increment of the scale factor, the number of industries requiring protection reduces; the level of investment in disruptive innovation increases; the ratio of optimal gains for the government in relation to the optimal gains for the firm reduces, and the same can be observed with regards to the relation between the optimal gains of the firm with protection and the optimal gains of the firm with no protection. Furthermore, for $A=1$, no protection is required and no investment in disruptive innovation takes place, as a consequence of the low level of reward for having a successful project.

In terms of implications, the present study can be of help in developing a better understanding of the role played by innovation in creating a competitive advantage for a firm. Additionally, the study can be of help to managers and practitioners by means of providing insightful thoughts into how innovation could be managed in an increasingly dynamic competitive landscape, wherein multiple aspects of both the innovation process and the business environment must be considered.

\section{Acknowledgement}

The authors would like to thank the Editor-in-Chief and the anonymous reviewers for their very helpful comments and suggestions made on the previous draft of this manuscript.

\section{References}

[1] Abernathy, W. J. (1978). The Productivity Dilemma: Roadblock to Innovation in the Automobile Industry. Baltimore: Johns Hopkins University Press.

[2] Abernathy, W. and Clark, K. B. (1985). Mapping the winds of creative destruction. Research Policy, 14, 3-22.

[3] Abernathy W. and Utterback J. (1978). Patterns of Industrial Innovation. Technology Review, 80, 40-47.

[4] Baregheh, A., Rowley, J. and Sambrook, S. (2009). Towards a multidisciplinary definition of innovation. Management Decision, 47(8), 1323-1339.

[5] Baregheh, A., Rowley, J., Sambrook, S. and Davies, D. (2012). Innovation in food sector SMEs. Journal of Small Business and Enterprise Development, 19(2), 300-321.

[6] Christensen, C. M. (1997). The innovators dilemma: When new technologies cause great firms to fail. Boston, MA: Harvard University Press.

[7] Damanpour, F. (1992). Organizational size and innovation. Organization Studies, 13(3), $375-402$.

[8] Day, G. (2013). Is it real? Can we win? Is it worth doing? Managing risk and reward in an innovation portfolio. On Innovation. HBR'S 10 must reads. Harvard Business Publishing.

[9] Drucker, P. (1994). Innovation \& Entrepreneurship. New York, NY: Harper \& Row. 
[10] Ettlie, J. E., Bridges, W. P. and O'Keefe, R. D. (1984). Organization strategy and structural differences for radical versus incremental innovation. Management Science, 30, 682-695.

[11] Francis, D. and Bessant, J. (2005). Targeting innovation and implications for capability development. Technovation, 25(3), 171-183.

[12] Hage, J. (1980). Theories of organizations. New York, NY: Wiley.

[13] Hall, L. A. and Bagchi-Sen, S. (2007). An analysis of firm-level innovation strategies in the US biotechnology industry. Technovation, 27, 4-14.

[14] Khazanchi, S., Lewis, M. W. and Boyer, K. (2007). Innovation-supportive culture: the impact of organizational values on process innovation. Journal of Operations Management, $25(4), 871-884$.

[15] Kim, W.C. and Mauborgne, R. (2005). Blue Ocean strategy: from theory to practice. California Management Review, 47(3).

[16] Kimberly, J. R. (1981). Managerial innovation. In P. C. Nystrom \& W. H. Starbuck (Eds.), Handbook of organizational design (1, 84-104). New York: Oxford University Press.

[17] Kimberly, J. R. and Evanisko, M. R. (1981). Organizational innovation. The influence of individual, organizational, and contextual factors on hospital adoption of technological and administrative innovations. Academy of Management Journal, 24, 689-713.

[18] Kozlowski, J. (2015). Innovation indices: The need for positioning them where they properly belong. Scientometrics, 104(3), 609-628.

[19] Lin, C. C., Yeh, J. L. and Hung, G. W. (2012). Internal Impediments of Organizational Innovation: An Exploratory Study. Journal of the Knowledge Economy, 3(2), 185-198.

[20] Lokshin, B., van Gils, A. and Bauer, E. (2008). Crafting firm competencies to improve innovative performance (Working Paper). UNU-MERIT, Maastricht. Retrieved from www.merit.unu.edu/publications/wppdf/2008/wp2008-009.pdf [Accessed 23/4/2016].

[21] Mothe, C. and Nguyen Thi, T. U. (2010). The link between non-technological innovations and technological innovation. European Journal of Innovation Management, 13(3), 313-332.

[22] Nord, W. R. and Tucker, S. (1987). Implementing routine and radical innovation. Lexington, MA: Lexington Books.

[23] Oke, A., Burke, G. and Myers, A. (2007). Innovation types and performance in growing UK SMEs. International Journal of Operations \& Production Management, 27(7), 735-753.

[24] Porter, M. E. (1986). Competition in the global industries. Boston, MA: Harvard Business School Press.

[25] Schmidt, T. and Rammer, C. (2007). Non-technological and technological innovation: strange bedfellows? (Working Paper 07-052). ZEW, Mannheim. Retrieved from http://ftp.zew.de/pub/zew-docs/dp/dp07052.pdf [Accessed 23/4/2016].

[26] Teece, D. J., Pisano, G. and Shuen, A. (1997). Dynamics capabilities and strategic management. Strategic Management Journal, 18(7), 509-533.

[27] Tushman, M. L. and Anderson, P. (1986). Technological discontinuities and organizational environments. Administrative Science Quarterly, 31(3), 439-465.

[28] Van de Ven, A. H. and Rogers, E. M. (1988). Innovation and organizations - critical perspectives. Communication Research, 15, 632-651. 


\section{Appendix}

The following table A1 shows the results of the numerical simulations for the cases of $A=1, A$ $=2, A=3$, and $A=5$.

\begin{tabular}{|c|c|c|c|c|c|c|c|c|c|}
\hline $\begin{array}{c}(0) \\
A \\
\end{array}$ & $\begin{array}{c}(1) \\
\beta \\
\end{array}$ & $\begin{array}{l}(2) \\
\delta^{*} \\
\end{array}$ & $\begin{array}{l}(3) \\
\alpha^{*} \\
\end{array}$ & $\begin{array}{l}(4) \\
\boldsymbol{W}^{*} \\
\end{array}$ & $\begin{array}{l}(5) \\
g^{*} \\
\end{array}$ & $\begin{array}{l}(6) \\
\boldsymbol{\pi}_{1}{ }^{*} \\
\end{array}$ & $\begin{array}{l}(7) \\
\boldsymbol{\Pi}_{2}{ }^{*} \\
\end{array}$ & $\begin{array}{c}(8) \\
\boldsymbol{w}^{*} / g^{*} \\
\end{array}$ & $\begin{array}{c}(9) \\
\boldsymbol{g}^{*} / \mathbf{g}^{+} \\
\end{array}$ \\
\hline 1 & $\begin{array}{c}0.1- \\
0.9 \\
\end{array}$ & 0.0 & 0.0 & 0.0000 & 0.0000 & 0.5000 & 0.5000 & nd & nd \\
\hline \multirow[t]{9}{*}{2} & 0.1 & 0.0 & 0.8 & 0.0040 & 0.1161 & 0.5000 & 0.5000 & 0.0345 & 1.0000 \\
\hline & 0.2 & 0.0 & 0.6 & 0.0120 & 0.0608 & 0.5000 & 0.5000 & 0.1974 & 1.0000 \\
\hline & 0.3 & 0.0 & 0.4 & 0.0180 & 0.0249 & 0.5000 & 0.5000 & 0.7237 & 1.0000 \\
\hline & 0.4 & 0.1 & 0.4 & 0.0219 & 0.0223 & 0.4737 & 0.5263 & 0.9809 & 3.9600 \\
\hline & 0.5 & 0.2 & 0.5 & 0.0278 & 0.0240 & 0.4444 & 0.5556 & 1.1553 & nd \\
\hline & 0.6 & 0.3 & $0.7^{\#}$ & 0.0296 & 0.0295 & 0.4118 & 0.5882 & 1.0038 & nd \\
\hline & 0.7 & 0.3 & 0.5 & 0.0391 & 0.0112 & 0.4118 & 0.5882 & 3.4867 & nd \\
\hline & 0.8 & 0.3 & $0.3^{\#}$ & $0.0367^{\#}$ & $0.0025^{\#}$ & 0.4118 & 0.5882 & $14.9421^{\#}$ & nd \\
\hline & 0.9 & 0.4 & 0.5 & 0.0394 & 0.0046 & 0.3750 & 0.6250 & 8.6268 & nd \\
\hline \multirow[t]{9}{*}{3} & 0.1 & 0.0 & 1.0 & 0.0050 & 0.3922 & 0.5000 & 0.5000 & 0.0127 & 1.0000 \\
\hline & 0.2 & 0.0 & 1.0 & 0.0200 & 0.2654 & 0.5000 & 0.5000 & 0.0754 & 1.0000 \\
\hline & 0.3 & 0.0 & 1.0 & 0.0450 & 0.1595 & 0.5000 & 0.5000 & 0.2822 & 1.0000 \\
\hline & 0.4 & 0.0 & 0.8 & 0.0640 & 0.0774 & 0.5000 & 0.5000 & 0.8268 & 1.0000 \\
\hline & 0.5 & 0.1 & 0.8 & 0.0737 & 0.0657 & 0.4737 & 0.5263 & 1.1207 & 2.4307 \\
\hline & 0.6 & 0.2 & 1.0 & 0.0933 & 0.0625 & 0.4444 & 0.5556 & 1.4930 & 16.6384 \\
\hline & 0.7 & 0.2 & 0.7 & 0.0980 & 0.0234 & 0.4444 & 0.5556 & 4.1872 & nd \\
\hline & 0.8 & 0.3 & 0.9 & 0.1101 & 0.0256 & 0.4118 & 0.5882 & 4.3085 & nd \\
\hline & 0.9 & 0.3 & 0.6 & 0.1048 & 0.0060 & 0.4118 & 0.5882 & 17.5214 & nd \\
\hline \multirow[t]{9}{*}{5} & 0.1 & 0.0 & 1.0 & 0.0050 & 0.9536 & 0.5000 & 0.5000 & 0.0052 & 1.0000 \\
\hline & 0.2 & 0.0 & 1.0 & 0.0200 & 0.7090 & 0.5000 & 0.5000 & 0.0282 & 1.0000 \\
\hline & 0.3 & 0.0 & 1.0 & 0.0450 & 0.4991 & 0.5000 & 0.5000 & 0.0902 & 1.0000 \\
\hline & 0.4 & 0.0 & 1.0 & 0.0800 & 0.3238 & 0.5000 & 0.5000 & 0.2470 & 1.0000 \\
\hline & 0.5 & 0.0 & 1.0 & 0.1250 & 0.1832 & 0.5000 & 0.5000 & 0.6823 & 1.0000 \\
\hline & 0.6 & 0.0 & 1.0 & 0.1800 & 0.0773 & 0.5000 & 0.5000 & 2.3298 & 1.0000 \\
\hline & 0.7 & 0.1 & 1.0 & 0.1953 & 0.0604 & 0.4737 & 0.5263 & 3.2346 & 3.7195 \\
\hline & 0.8 & 0.2 & 1.0 & 0.1956 & 0.0497 & 0.4444 & 0.5556 & 3.9315 & nd \\
\hline & 0.9 & 0.2 & 0.8 & 0.2080 & 0.0102 & 0.4444 & 0.5556 & 20.4701 & nd \\
\hline
\end{tabular}

Note. \# = Discretization effects, the behavior of the variable shows a relative anomaly fluctuation, but not in terms of tendency. $\mathrm{Nd}=$ Not defined, division by zero, corresponding to unlimited magnitude.

Table A1: Optimal system behavior under legal protection. 